\section{A female with pulmonary artery hypertension and pleural effusion}

\section{Case report}

A 42-year-old Caucasian female was admitted to hospital with a history of dyspnoea at rest. Apart from a history of nodular prurigo for which she used topical steroid creams, the patient was generally healthy. The patient reported that shortness of breath had started 3 months ago, initially on exertion, but now had progressed to dyspnoea at rest. In addition, the patient was experiencing orthopnoea and required four pillows at night. There was no history of chest pain, cough, wheeze, haemoptysis or expectoration of phlegm. However, there was a history of frequent and loose stools with non-specific abdominal discomfort over the same time period.

The patient was single and worked as a secretary in an office, had never smoked and drank alcohol only occasionally. She never kept any pets and had not travelled abroad recently. There was no history of recreational drug use.

There was no family history of ischaemic heart disease, autoimmune disease or thromboembolic disease.

On examination, the patient was dyspnoeic, tachypnoeic, mildly jaundiced and had pedal oedema. She was in sinus rhythm with a ventricular rate of 88 beats per minute and her blood pressure was 130/90 mmHg. Heart sounds were normal with a pansystolic murmur in the tricuspid area. The jugular venous pressure was raised up to her earlobes and large v-waves were present. A left parasternal heave was present. The breath sounds were inaudible on the right mid and lower zones and the percussion note was stony dull. There were no rhonchi or crackles. She had a pulsatile enlarged liver with mild tenderness. There was no guarding or rebound tenderness, and bowel sounds were normal.

\section{Investigations}

On admission, haemoglobin, platelet count, mean cell volume, mean cell haemoglobin and erythrocyte sedimentation rate were normal. She had a white blood cell count of 14.0 (normal 4-11.0) and an international normalised ratio of 1.6. Renal function tests were normal. The level of serum aspartate aminotransferase was marginally raised at $57 \mathrm{IU} \cdot \mathrm{L}^{-1}$ (normal 7-40), bilirubin was $54 \mu \mathrm{mol}$ (normal 2-17) and alkaline phosphatase was also marginally raised at $136 \mathrm{U} \cdot \mathrm{L}^{-1}$ (normal 40-100). An autoimmune screen was negative. Chest radiography was performed (figure 1).

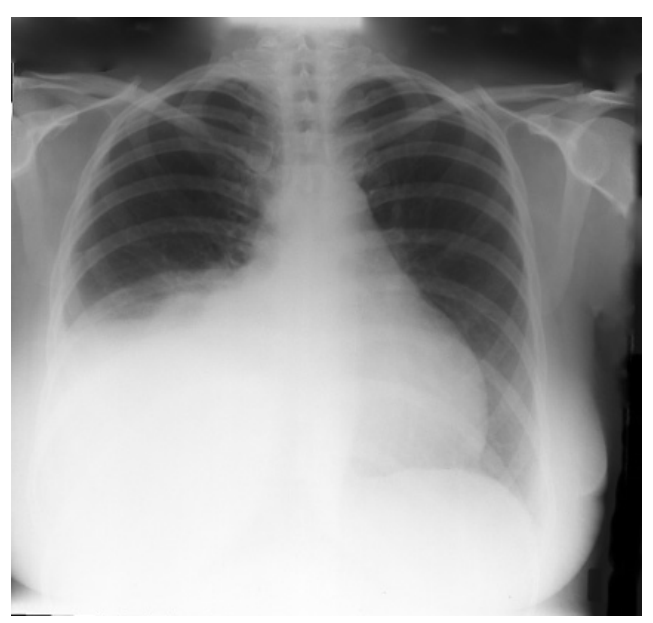

Figure 1

Chest radiograph.

\section{Task 1}

Interpret the chest radiograph.

\section{P. Bhatia ${ }^{1}$ \\ S. Karthik ${ }^{1}$ \\ R. Katira ${ }^{2}$ \\ E. Li-Kam-Wa ${ }^{3}$ \\ (n)}

Depts of ${ }^{1}$ Respiratory Medicine and ${ }^{2}$ Cardiology, and ${ }^{3}$ Chest Clinic, Blackpool Victoria Hospital, Blackpool, UK.

\section{Correspondence: \\ P. Bhatia \\ Dept of Respiratory Medicine \\ Blackpool Victoria Hospital \\ Whinney Heys Road \\ Blackpool \\ FY3 8NR \\ UK \\ E-mail:naviapo@aol.com}




\section{Answer 1}

Chest radiography confirms the presence of right-sided pleural effusion.

ECG revealed that the patient was in sinus rhythm, and, subsequently, an echocardiogram was performed (figure 2).

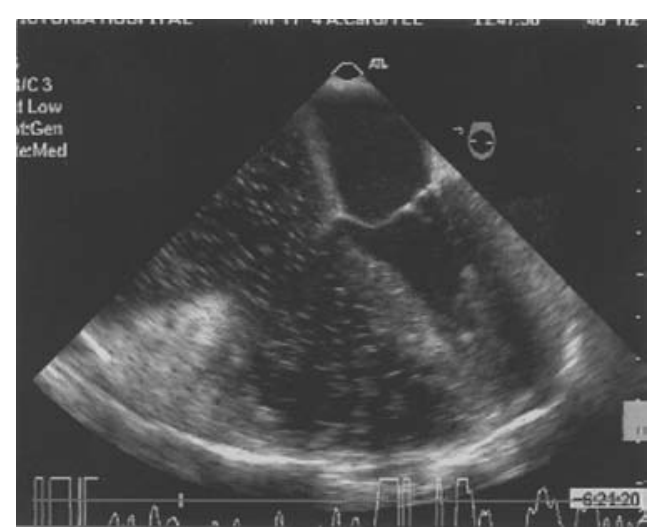

Figure 2

Echocardiogram.

\section{Task 2}

Interpret the echocardiogram.

\section{Answer 2}

The right heart chambers are severely dilated, whereas left ventricle function and size are normal. The septum is pushed into the left ventricle, resulting in a reduction of the left ventricle cavity size.

In addition, there was gross tricuspid regurgitation, with an estimated pulmonary artery pressure of $41 \mathrm{mmHg}$.

A computed tomography pulmonary angiogram of the chest excluded pulmonary emboli. A diagnostic tap of the pleural fluid revealed the protein level was $35 \mathrm{~g}^{-\mathrm{L}^{-1}}$ (serum protein $73 \mathrm{~g}^{-\mathrm{L}^{-1}}$ ), lactate dehydrogenase (LDH) was 395 $\mathrm{IU} \cdot \mathrm{L}^{-1}$ (serum LDH 825) and glucose was 5.7 $\mathrm{mmol} \cdot \mathrm{L}^{-1}$. Bacteriological and cytological examinations of the pleural fluid were normal. A clinical diagnosis was made, but the patient deteriorated rapidly and died before a definite diagnosis could be made. A post mortem confirmed the clinical suspicion.

\section{Task 3}

Based on the evidence presented, what would your diagnosis be? 


\section{Answer 3}

Pulmonary veno-occlusive disease (PVOD).

\section{Discussion}

Various processes can cause pulmonary hypertension, which is defined by the World Health Organization as a systolic pulmonary artery pressure of $>40 \mathrm{mmHg}$. PVOD is a rare form of primary pulmonary hypertension (PPH) in which progressive obstruction of the pulmonary veins leads to elevated blood pressure in the pulmonary arteries. It can affect all age groups, but the majority of cases occur in children and young adults.

PVOD has been associated with viral infections (influenza-like illness, measles [1], Epstein-Barr infection or cytomegalovirus infection [2]), toxin exposure (silica, soda ash, trichloro-S-triazinetriome [3]), chemotherapy [4] (bleomycin, mitomycin and carmustine) and as a complication following bone marrow transplantation $[5,6]$. It has also been reported in a patient with HIV infection [7]. HofFSTEIN et al. [8] have described a young female with sarcoidosis who presented with pulmonary hypertension that simulated PVOD. VoORDES et al. [9] diagnosed PVOD in a male infant who died aged 3 months. Two years earlier, a brother of the patient had died of the same disease at the age of 8 weeks. Therefore, it was suggested that the disease may have been caused by a viral infection, with the mother acting as a carrier.

Dyspnoea and syncope are the commonest symptoms, although chronic cough may be a presenting symptom in some patients [10]. As the pulmonary hypertension becomes more severe, cyanosis, chest pain, right upper quadrant pain due to hepatic congestion, and exertion syncope may occur. Orthopnoea is commonly seen in patients with PVOD, but is unusual in those with idiopathic pulmonary arterial hypertension (IPAH). On rare occasions, patients with PVOD may present with diffuse alveolar haemorrhage and sudden death. In a recent paper by RABILLER et al. [11], occult alveolar haemorrhage diagnosed by bronchoalveolar lavage was a common feature of PVOD.

Physical examination shows findings consistent with pulmonary hypertension of any cause.
Clubbing is an unusual feature. Orthopnoea, paroxysmal nocturnal dyspnoea, haemoptysis and pleural effusions are frequently seen in PVOD, but are rare in patients with IPAH. In PVOD, the pulmonary capillary and visceral pleural capillary hydrostatic pressures are elevated due to the post-capillary obstruction, leading to transudation of fluid into the pleural space [12]. In contrast, the high-resistance vessels are proximal to the pulmonary capillaries in IPAH and increased accumulation of pleural fluid does not occur.

PVOD should be suspected in any patient with the combination of pulmonary arterial hypertension, radiographic features of pulmonary oedema and a normal pulmonary artery occlusion pressure. Chest radiography may show signs of pulmonary hypertension with prominent Kerley B lines in the absence of other indications of left heart failure. MATTHEws and BUCHANAN [13] found intense hyperaemia of the lobar and segmental bronchi with vascular engorgement in the form of brightred longitudinal streaks in PVOD. An echocardiogram may show dilated right heart chambers with tricuspid regurgitation, and normal left heart size and function. Pulmonary function studies reveal a reduced diffusing capacity for carbon monoxide with preservation of lung volumes, similar to that found in other causes of pulmonary hypertension.

PVOD cannot be distinguished with certainty from IPAH by right heart catheterisation, unless the pulmonary capillary wedge pressure is elevated. The initial wedge pressure measurement in PVOD may be elevated; however, if the catheter is left in place for a short while and blood continues to drain towards the left atrium, the wedge pressure will normalise as there is no venous obstruction in the large veins.

The definite diagnosis can be made by lung biopsy if the patient is suitable to undergo the procedure. This will show fibrous intimal obliteration of venules with acute or recanalised thrombi.

The prognosis of PVOD is poor, and most patients die within 2 years of diagnosis [14]. Lung transplantation is the only therapy that can prolong the lives of patients with PVOD. The experience with lung transplantation in PVOD is not extensive; however, recurrence has not been reported thus far [15]. 


\section{Editorial comment}

PVOD is a rare and poorly understood syndrome that probably represents a final common pathway of disease caused by a variety of insults. It has a similar clinical presentation to PPH, with progressive dyspnoea and elevated pulmonary artery pressure.

The importance of diagnosing the condition is largely due to its poorer prognosis than primary hypertension; this necessitates more rapid evaluation and listing for lung transplantation. Chest radiography may occasionally distinguish PVOD from PPH by the presence of peripheral interstitial infiltrates or septal lines. Chest CT can display interlobular septal thickening, mosaic ground-glass opacity, effusions and mediastinal lymphadenopathy.

The pathological hallmark of PVOD is the extensive and diffuse occlusion of pulmonary veins by fibrous tissue, which may be loose and oedematous or dense and sclerotic, with the former probably reflecting an earlier stage in the development of the lesion. The most consistent parenchymal change is interstitial oedema, which is best observed in lobular septa.

PVOD can be diagnosed definitely only by surgical lung biopsy, and this procedure should be considered to confirm the clinical suspicion.

Although there are reports of successful treatment of PVOD with calcium channel blockers or epoprostenol, fulminant pulmonary oedema and death have also been reported, and, in general, medical therapy is ineffective.

Future research is required to more precisely define the risk factors for this condition and to determine optimal therapy. Using molecular biology techniques such as PCR, we can better clarify the role of exon 1 of the bone morphogenetic protein receptor II gene, a member of the transforming growth factor- $\beta$ receptor family, resulting in histopathologically proven PVOD.

G. Biscione, Italy

\section{References}

1. Brown CH, Harrison CV. Pulmonary veno-occlusive disease. Lancet 1966; 2: 61-65.

2. McDonnell PJ, Summer WR, Hutchins GM. Pulmonary veno-occlusive disease. Morphological changes suggesting a viral cause. JAMA 1981; 246: 667-671.

3. Liu L, Sackler JP. A case of pulmonary veno-occlusive disease: etiological and therapeutic appraisal. Angiology 1973; 23: 299-304.

4. Doll DC, Yarbro JW. Vascular toxicity associated with chemotherapy and hormonotherapy. Curr Opin Oncol 1994; 6: 345-350.

5. Williams LM, Fussell S, Veith RW, Nelson S, Mason CM. Pulmonary veno-occlusive disease in an adult following bone marrow transplantation. Chest 1996; 109: 1388-1391.

6. Troussard X, Bernaudin JF, Cordonnier C, et al. Pulmonary veno-occlusive disease after bone marrow transplantation. Thorax 1984; 39: 956-957.

7. Escamilla R, Hermant C, Berjaud J, Mazerolles C, Daussy X. Pulmonary veno-occlusive disease in a HIV-infected intravenous drug abuser. Eur Respir J 1995; 8: 1982-1984.

8. Hoffstein V, Ranganathan N, Mullen JB. Sarcoidosis simulating pulmonary veno-occlusive disease. Am Rev Respir Dis 1986; 134: 809-811.

9. Voordes CG, Kuipers JR, Elema JD. Familial pulmonary veno-occlusive disease: a case report. Thorax 1977; 32: 763-766.

10. Calderon M, Burdine JA. Pulmonary veno-occlusive disease. J Nucl Med 1974; 15: 455-457.

11. Rabiller A, Jaïs X, Hamid A, et al. Occult alveolar haemorrhage in pulmonary veno-occlusive disease. Eur Respir J 2006; $27:$ 108-113.

12. Weiner-Kronish JP, Goldstein R, Matthay RA, et al. Lack of association of pleural effusion with chronic pulmonary arterial and right atrial hypertension. Chest 1987; 92: 967-970.

13. Matthews AW, Buchanan R. A case of pulmonary veno-occlusive disease and a new bronchoscopic sign. Respir Med 1990; 84: 503-505.

14. Shackelford GD, Sacks EJ, Mullins JD, McAlister WH. Pulmonary veno-occlusive disease: case report and review of literature. AJR Am J Roentgenol 1977; 128: 643-648.

15. Stewart S, McNeil K, NashefSA, Wells FC, Higenbottam TW, Wallwork J. Audit of referral and explant diagnoses in lung transplantation: a pathologic study of lungs removed for parenchymal disease. J Heart Lung Transplant 1995; 14: 1173-1186. 